02

\title{
Собственные центры люминесценции керамических иттрий-алюминиевого граната и оксида иттрия
}

\author{
() В.И. Соломонов ${ }^{1,2}$, В.В. Осипов ${ }^{1}$, В.А. Шитов ${ }^{1}$, К.Е. Лукьяшин ${ }^{1}$, А.С. Бубнова ${ }^{1}$ \\ ${ }^{1}$ Институт электрофизики Уральского отделения РАН, \\ 620016 Екатеринбург, Россия \\ ${ }^{2}$ Уральский федеральный университет, \\ 620002 Екатеринбург, Россия \\ e-mail: plasma@iep.uran.ru
}

Поступила в редакцию 15.03.2019 г.

В окончательной редакции 15.03.2019 г.

Принята к публикации 26.09.2019 г.

В диапазоне 220-850 nm исследована импульсная катодолюминесценция беспримесных, а также активированных иттербием и церием керамических образцов иттрий-алюминиевого граната и оксида иттрия с целью уточнения природы их собственных центров люминесценции. Показано, что в этих материалах присутствуют три типа собственных центра люминесценции: 1) автолокализованные экситоны с дырочной компонентой, представляющей собой молекулярные ионы $\mathrm{O}_{3}^{-2}$, ассоциированные с катионными вакансиями, излучающие одну полосу при $\lambda \approx 350 \mathrm{~nm}$ в оксиде иттрия и двойную полосу при $\lambda \approx 320$ и 350 пт в иттрийалюминиевом гранате; 2) $F$-центры, излучающие широкую полосу при $\lambda \approx 490 \mathrm{~nm}$ в оксиде иттрия и при $\lambda \approx 510 \mathrm{~nm}$ в иттрий-алюминиевом гранате; 3) связанный радикал $\mathrm{Y}=\mathrm{O}$, излучающий серию узких полос в области 600-730 nm в обоих материалах. Показано, что активация обоих материалов иттербием не оказывает влияния на характеристики первого центра, но сильно влияет на характеристики второго и третьего центров.

Ключевые слова: импульсная катодолюминесценция, $F$-центр, автолокализованный экситон, отжиг керамики.

DOI: $10.21883 /$ OS.2020.01.48831.117-19

\section{Введение}

В настоящее время высокопрозрачные керамики на основе иттрий-алюминиевого граната (YAG) и оксида иттрия находят применение в качестве активных элементов твердотельных лазеров [1-4] и люминофоров [5]. Керамики представляют собой поликристаллы, отличающиеся от монокристаллов наличием межкристаллитных границ и повышенной пористостью до 1-500 ppm. Поэтому в керамических элементах могут присутствовать собственные центры люминесценции такого же типа как в монокристаллах, так и присущие только керамике.

Исследованию собственной люминесценции монокристаллов YAG посвящен ряд работ [6-12]. Полосы собственной люминесценции обнаружены в ультрафиолетовой $(У Ф)$ и зеленой областях спектра при $\lambda \approx 350$ и $510 \mathrm{~nm}$ соответственно. Интенсивная УФ люминесценция беспримесного YAG впервые исследовалась в [6], где был сделан вывод о ее собственной природе. В [7] предположили, что она излучается тетрагональными комплексами $\left(\mathrm{AlO}_{4}\right)^{5-}$. В $[10,11]$ УФ полосу связывали с рекомбинацией свободных электронов и автолокализованных дырок. Причем эти дырки расположены на ионах кислорода, находящихся в ближайшем окружении антиузельных дефектов, возникающих в результате вхождения ионов $\mathrm{Y}^{3+}$ в октаэдрические узлы ионов $\mathrm{Al}^{3+}$. В [8] УФ полосы собственного свечения YAG приписали автолокализованным экситонам (АЛЭ). Данная модель предусматривает дырочную компоненту АЛЭ в виде молекулы $\mathrm{O}_{3}^{-2}$, аналогичной $V_{k}$-центру в щелочногалоидных кристаллах [9]. Собственное свечение YAG в зеленой области спектра авторами [12] связывается с люминесценцией $F^{+}$- и $F$-центров.

В связи с трудностью выращивания больших монокристаллов собственная люминесценция оксида иттрия изучалась в тонких пленках и порошках микронного размера [13-16]. В термо- [13], катодо- [14], рентгенолюминесценции $[15,16]$, а также при возбуждении азотным лазером $(\lambda=337.2 \mathrm{~nm})[15,16]$ в них обнаружена широкая неэлементарная полоса в области 295-500 nm. Ее форма остается сплошной даже при криогенной температуре образцов. Анализ поведения полосы позволил авторам $[15,16]$ выделить в ней и идентифицировать шесть компонент. В частности, компонента при $\lambda \approx 427 \mathrm{~nm}$ по их предположению излучается кислородными вакансиями. Компоненты при $\lambda \approx 477,528,590$ и $652 \mathrm{~nm}$ представляют рекомбинационное излучение донорноакцепторных пар $\mathrm{Y}^{3+}-\mathrm{O}^{2-}$. При исследовании импульсной катодолюминесценции микроразмерных порошков и керамики оксида иттрия в [17] вместо сплошной полосы в области 420-800 nm обнаружена серия узких линий. Часть из них была приписана излучению радикалов $\mathrm{Y}=\mathrm{O}$ на переходах ${ }^{2} \Pi_{1 / 2,3 / 2}\left(V^{\prime}=0,1\right) \rightarrow X^{2} \Sigma\left(V^{\prime \prime}=0.1\right)$ с участием фононов. В этой работе показано, что такие радикалы образуются на свободной поверхности пор и 
микротрещин и остаются связанными с кристаллической решеткой ионами иттрия.

Таким образом, в монокристаллах YAG и порошках оксида иттрия однозначно показано наличие собственной люминесценции, но достоверно не установлена природа излучающих ее центров. Данная работа направлена на исследование собственной люминесценции в керамических YAG и оксиде иттрия с целью уточнения природы ее центров излучения и влияния на них примесных центров. Для этого исследовались спектры импульсной катодолюминесценции как номинально чистых (беспримесных), так и активированных иттербием и церием керамических образцов. Использование этих ионов-активаторов мотивировалось тем, что ион $\mathrm{Yb}^{3+}$ не имеет, а ион $\mathrm{Ce}^{3+}$ имеет полосы поглощения и люминесценции в области излучения собственных центров.

\section{Объекты исследования и аппаратура}

Керамика синтезировалась из нанопорошков простых оксидов $\mathrm{Al}_{2} \mathrm{O}_{3}, \mathrm{Y}_{2} \mathrm{O}_{3}, \mathrm{Yb}_{2} \mathrm{O}_{3}$ и $\mathrm{CeO}$, полученных методом лазерной абляции, по технологии, описанной в $[3,4]$. Прессованные нанопорошки необходимого состава (диски диаметром $14 \mathrm{~mm}$, толщиной $3 \mathrm{~mm}$ и плотностью около 0.5 от рентгеновской плотности граната или оксида иттрия) спекались в вакуумной печи графитовыми нагревателями в течении $20 \mathrm{~h}$ при температуре $1700-1800^{\circ} \mathrm{C}$. Синтез керамики проводился без спекающих добавок для исключения их влияния на спектры люминесценции и пропускания. Полученная после этой процедуры керамика имела темную окраску из-за дефицита кислорода, образовавшегося в результате его испарения (возгонки) в вакууме при высокой температуре. Поэтому керамика подвергалась просветляющему отжигу на воздухе в течение 5-10 h при температуре $1300^{\circ} \mathrm{C}$. По данным рентгенофазового анализа, проведенного на дифрактометре D8 Discover, керамические образцы были однофазными и имели кристаллическую структуру иттрийалюминиевого граната и кубического оксида иттрия соответственно. Для исследований были изготовлены 6 образцов номинально чистой керамики YAG, 2 образца $5 \mathrm{Yb}: \mathrm{YAG}, 4$ образца $10 \mathrm{Yb}:$ YAG и 2 образца $0.5 \mathrm{Ce}: \mathrm{YAG}$ с содержанием оксида иттербия 5 и $10 \mathrm{~mol} \%$ и оксида церия $0.5 \mathrm{~mol} \%$ соответственно, а также по 2 образца номинально чистого $\left(\mathrm{Y}_{2} \mathrm{O}_{3}\right)$ и активированного $5 \mathrm{~mol} \%$ иттербием оксида иттрия $\left(5 \mathrm{Yb}: \mathrm{Y}_{2} \mathrm{O}_{3}\right)$. В ходе исследований часть образцов подвергались дополнительному отжигу на воздухе в течение $5 \mathrm{~h}$ при температуре $1300^{\circ} \mathrm{C}$.

Распределение пор по глубине керамических образцов подсчитывалось с помощью оптического микроскопа Olympus. Для этого выбиралась область в центральной части образца, равная $577 \times 433 \mu \mathrm{m}^{2}$. Сканирование сквозь толщу всего образца осуществлялось с шагом $50 \mu \mathrm{m}$. Размер одного обрабатываемого слоя $577 \times 433 \times 50 \mu \mathrm{m}^{3}$. Поры условно подразделялись на крупные (более $2 \mu \mathrm{m})$ и мелкие (менее $2 \mu \mathrm{m})$. Подсчет размеров крупных пор осуществлялся в индивидуальном порядке. Мелкие поры имели, как правило, сферическую форму, поэтому для исчисления их полного объема средний размер такого центра умножался на их количество.

Спектры пропускания керамик снимались с помощью спектрофотометра Shimadzu UV-1700 в диапазоне от 200 до $1100 \mathrm{~nm}$ при комнатной температуре образцов. Для всех образцов YAG пропускание света в области $800 \mathrm{~nm}$ превышало 60\%, в то время как для образцов оксида иттрия пропускание не превышало $30 \%$.

Импульсную катодолюминесценцию (ИКЛ) возбуждали и исследовали на установке КЛАВИ [18]. Перед исследованием образцы не подвергали специальной обработке, их облучали в воздухе при комнатной температуре электронным пучком длительностью $2 \mathrm{~ns}$ при плотности тока $160 \mathrm{~A} / \mathrm{cm}^{2}$ и средней энергии электронов $180 \mathrm{keV}$. Интегральный по времени свечения спектр в диапазоне 220-850 nm регистрировался двумя многоканальными фотоприемниками. Диапазон чувствительности первого фотоприемника составлял 220-500 nm, а второго - 350-850 nm. Сшивка спектров проводилась на длине волны $400 \mathrm{~nm}$. При этом масштабы измеряемой интенсивности люминесценции разных фотоприемников не корректировались между собой. Градуировка каждого фотоприемника осуществлялась по шкале длин волн с помощью эталонной ртутно-аргоновой спектральной лампы HG-1 фирмы Ocean Optics, по шкале интенсивности с помощью галогенной эталонной лампы AvaLightHAL-CAL фирмы Avantes. Спектральная информация усреднялась по 20 импульсам. При этом стабильность амплитудных параметров спектра ИКЛ керамики монокристаллов составляла более 90\%. Погрешность измерения длины волны не превышала $\pm 0.5 \mathrm{~nm}$.

\section{Результаты исследований и их обсуждение}

Содержания пор для разных образцов составляли от 20 до 400 ppm. Наибольшее количество пор наблюдалось в оксиде иттрия и номинально чистых образцах YAG. Дополнительный просветляющий отжиг образцов на воздухе при температуре $1300^{\circ} \mathrm{C}$ в течение $5 \mathrm{~h}$ не оказывал заметного влияния на содержание пор.

На рис. 1 представлены спектры пропускания исследованных образцов YAG. Во всех спектрах присутствуют две УФ полосы поглощения с максимумами при $\lambda \approx 255$ и $340 \mathrm{~nm}$, а также синяя полоса при $\lambda \approx 455 \mathrm{~nm}$, слабо выраженная в номинально чистых образцах YAG. В активированных иттербием керамиках YAG в ближней ИК области присутствует сильная хорошо структурированная полоса поглощения примесного иона $\mathrm{Yb}^{3+}$. В образцах Ce:YAG наблюдаются усиленные полосы поглощения при $\lambda \approx 255,340$ и $455 \mathrm{~nm}$, а также дополнительная полоса при $\lambda \approx 300 \mathrm{~nm}$. 


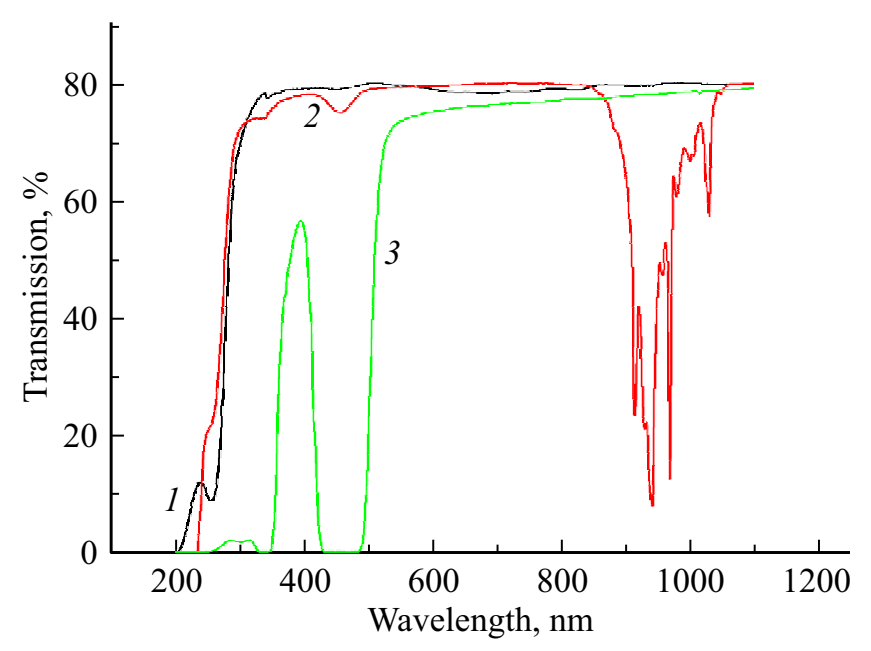

Рис. 1. Спектры пропускания образцов керамики номинально чистого YAG (1) и активированных 10Yb:YAG (2), $0.5 \mathrm{Ce}: \mathrm{YAG}(3)$.

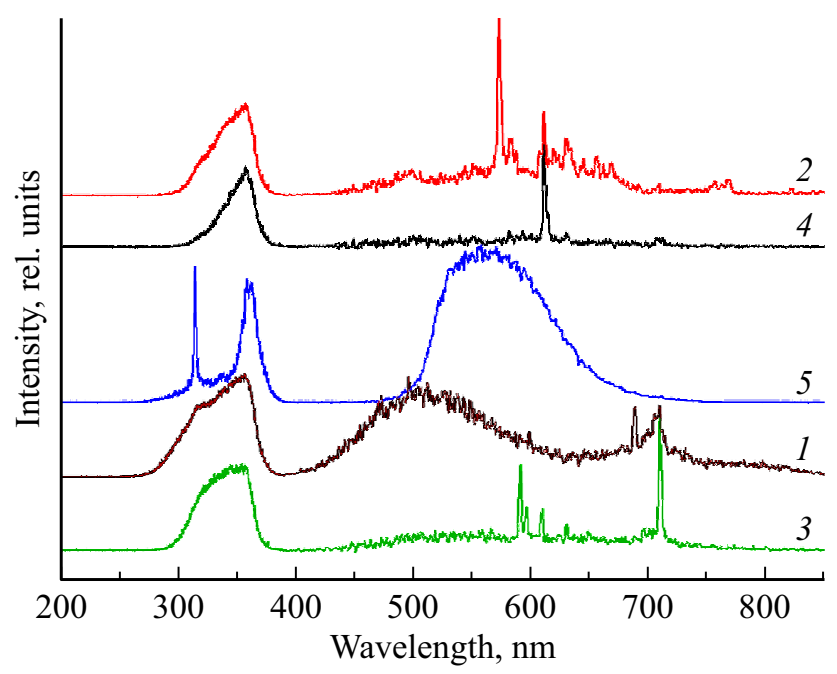

Pис. 2. Спектры ИКЛ керамики номинально чистых YAG (1) и $\mathrm{Y}_{2} \mathrm{O}_{3}(2)$, а также активированных иттербием $10 \mathrm{Yb}$ : YAG (3), $5 \mathrm{Yb}: \mathrm{Y}_{2} \mathrm{O}_{3}(4)$ и церием $0.5 \mathrm{Ce}: \mathrm{YAG}(5)$.

На рис. 2 приведены спектры импульсной катодолюминесценции керамических образцов YAG и оксида иттрия.

Во всех спектрах присутствует сильная ультрафиолетовая полоса люминесценции в области $275-375 \mathrm{~nm}$. В образцах оксида иттрия она имеет синглетный характер с центром при $\lambda \approx 350 \mathrm{~nm}$, а в YAG она состоит из двух полос с максимумами при $\lambda \approx 320$ и $350 \mathrm{~nm}$ (рис. 3). Причем примесь иттербия не оказывает влияния на ее форму в обеих кристаллических матрицах, в то время как в образцах Се:YAG она искажается присутствием сильной линии при $\lambda \approx 314 \mathrm{~nm}$ и узкой полосы при $\lambda \approx 360 \mathrm{~nm}$.

При дополнительном отжиге образцов керамики на воздухе при температуре $1300^{\circ} \mathrm{C}$ в течение 5 h контур и интенсивность УФ полосы практически не изменяются (рис. 3). Это указывает на то, что центр излучения этой полосы не связан с кислородными вакансиями, содержание которых уменьшается при такой процедуре.

В [7] предполагали, что полосы УФ люминесценции при $\lambda \approx 320$ и $350 \mathrm{~nm}$ в неактивированных монокристаллах излучаются тетрагональными комплексами $\left(\mathrm{AlO}_{4}\right)^{5-}$. Однако это предположение сомнительно, так как в природных минералах излучение этих центров наблюдается в области длин волн больше $460 \mathrm{~nm}$ [19].

В [10,11] УФ полосу связывали с рекомбинацией свободных электронов с автолокализованными дырками, расположенными на ионах кислорода, находящихся в ближайшем окружении антиузельных дефектов, возникающих в результате вхождения ионов $\mathrm{Y}^{3+}$ в октаэдрические узлы ионов $\mathrm{Al}^{3+}$. Эту модель нельзя применить к оксиду иттрия, так как в нем не могут возникать дефекты такого типа. В тоже время совпадение УФ полосы излучения оксида иттрия с длинноволновой компонентой УФ полосы YAG (рис. 3) указывает на то, что эту модель нельзя применить в полной мере и к YAG.

В [8] УФ полосы собственного свечения YAG приписывали автолокализованным экситонам (АЛЭ), в которых дырочная компонента представлена в виде молекулы $\mathrm{O}_{3}^{-2}$. Если эти молекулы ассоциированы с катионными вакансиями, то такая модель АЛЭ соответствует наблюдаемым фактам. А именно в оксиде иттрия может образовываться только один тип дырочного центра $\mathrm{O}_{3}^{-2}$, ассоциированного с вакансией $\mathrm{Y}^{3+}$. Этот центр излучает полосу при $\lambda \approx 350 \mathrm{~nm}$. В YAG могут образовываться два типа центров, ассоциированных с вакансиями $\mathrm{Y}^{3+}$ и $\mathrm{Al}^{3+}$. Первый центр излучает полосу при $\lambda \approx 350 \mathrm{~nm}$, как в оксиде иттрия, а второй - при $\lambda \approx 320 \mathrm{~nm}$. Этим полосам люминесценции соответствуют полосы поглощения при $\lambda \approx 340$ и $255 \mathrm{~nm}$ (рис. 1). Кроме того, именно такой молекулярный ион $\mathrm{O}_{3}^{-2}$ обеспечивает ком-

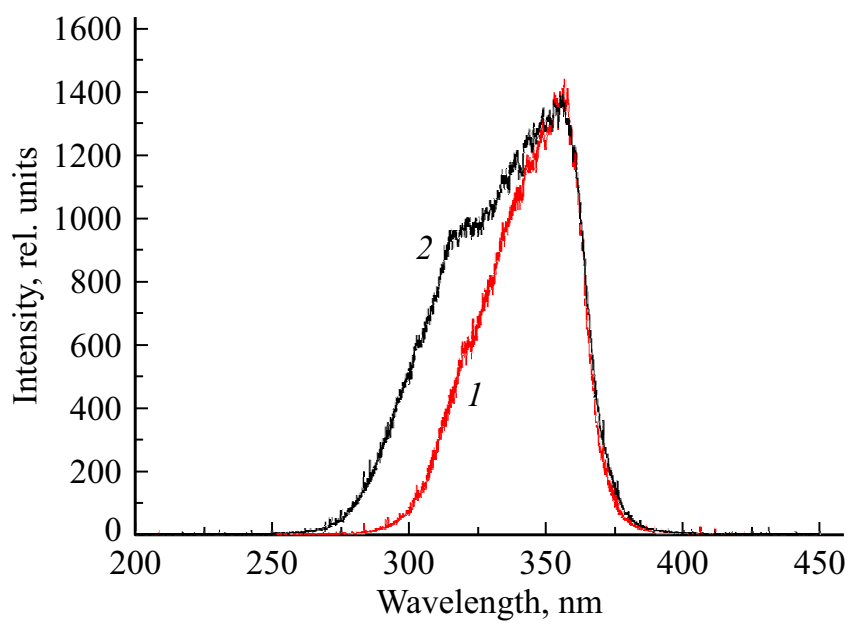

Рис. 3. УФ полоса ИКЛ номинально чистых образцов керамики из оксида иттрия (1) и YAG (2). 


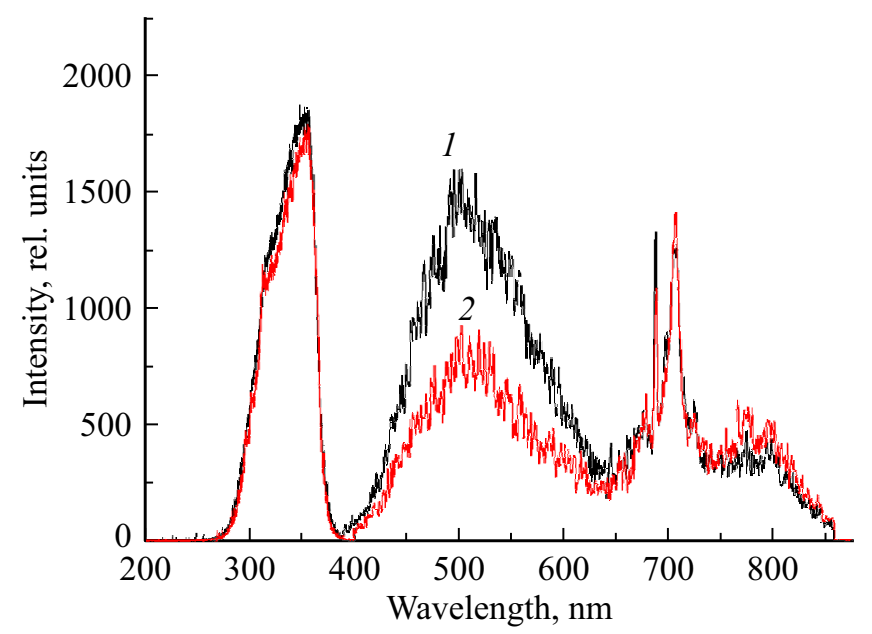

Pис. 4. Спектры YAG одного и того же номинально чистого образца YAG не подвергнутого (1) и подвергнутого дополнительному отжигу на воздухе (2).

пенсацию электрического заряда в позиции катионной вакансии.

Зеленая полоса люминесценции при $\lambda \approx 510 \mathrm{~nm}$ явно выделяется только в образцах номинально чистой керамики YAG (рис. 2). В образцах YAG, активированных иттербием, эта полоса существенно ослабляется. В керамике Ce:YAG она маскируется сильной полосой люминесценции иона $\mathrm{Ce}^{3+}$. При дополнительном отжиге образцов керамики YAG на воздухе при температуре $1300^{\circ} \mathrm{C}$ в течение $5 \mathrm{~h}$ интенсивность зеленой полосы люминесценции при $\lambda \approx 510 \mathrm{~nm}$ почти двукратно уменьшается в номинально чистых образцах (рис. 4) и более слабо уменьшается в образцах Yb:YAG. В образцах керамики из оксида иттрия, как чистой, так и активированной иттербием, наблюдается слабая широкая полоса при $\lambda \approx 490 \mathrm{~nm}$ (рис. 2).

B [12] свечение YAG в зеленой области спектра в виде широкой полосы при $\lambda \approx 510 \mathrm{~nm}$ связывается с люминесценцией $F^{+}$- или $F$-центров. Наблюдаемое нами снижение интенсивности этой полосы после дополнительного отжига керамики на воздухе не противоречит этому предположению. (При таком отжиге керамика насыщается кислородом, при этом уменьшается концентрация кислородных вакансий). То есть полосу при $\lambda \approx 510 \mathrm{~nm}$ в керамике YAG следует связать с излучением одного из $F^{+}$или $F$-центров. В простых оксидах, например в корунде, оба эти центра активны в люминесценции, излучая в области $330 \mathrm{~nm}\left(F^{+}\right)$и $420 \mathrm{~nm}(F)$ [20]. В случае керамических образцов YAG и оксида иттрия наблюдается только по одной широкой полосе люминесценции при $\lambda \approx 490 \mathrm{~nm}$ в оксиде иттрия и при $\lambda \approx 510 \mathrm{~nm}$ в YAG, которые следует отождествить с излучением более устойчивых $F$-центров.

В красной области спектра ИКЛ всех исследованных образцов наблюдаются серии узких линий. Ранее было показано [17], что в чистом оксиде иттрия серия узких линий излучается радикалами $\mathrm{Y}=\mathrm{O}$ на переходах ${ }^{2} \Pi_{1 / 2,3 / 2}\left(V^{\prime}=0.1\right) \rightarrow X^{2} \Sigma\left(V^{\prime \prime}=0.1\right)$ с участием фононов. Эти радикалы образуются на свободной поверхности пор и микротрещин и остаются связанными с кристаллической решеткой через ионы иттрия. Причем интенсивность этих линий возрастает с ростом содержания пор в керамике, в то время как с увеличением содержания пор снижается коэффициент пропускания керамики. Серия узких линий $(\lambda \approx 667$, $688,707$ и $725 \mathrm{~nm})$ в чистом YAG имеет такую же природу, как и в оксиде иттрия. Отличие заключается в том, что в YAG более активны оптические переходы ${ }^{2} \Pi_{1 / 2,3 / 2}\left(V^{\prime}=0\right) \rightarrow X^{2} \Sigma\left(V^{\prime \prime}=2.3\right)$ (волновое число собственных колебаний $\left.v=861 \mathrm{~cm}^{-1}\right)$. Их интенсивность, как и в оксиде иттрия, не изменяется после дополнительного отжига керамики в воздухе (рис. 4), так как такой отжиг не оказывает влияния на содержание пор. В спектре пропускания номинально чистого YAG (рис. 1) этим линиям ИКЛ соответствует слабая широкая полоса в диапазоне $550-850 \mathrm{~nm}$.

При активировании иттербием в спектре ИКЛ $\mathrm{Yb}: \mathrm{Y}_{2} \mathrm{O}_{3}$ остается одна линия при $611 \mathrm{~nm}$, а в $\mathrm{Yb}: \mathrm{YAG}$ появляется серия новых линий при $\lambda \approx 691,697,610$, 631 и $710 \mathrm{~nm}$. При этом из спектра пропускания исчезает широкая полоса в диапазоне 550-850 nm, но усиливается полоса при $455 \mathrm{~nm}$ (рис. 1). Дополнительный отжиг керамики $\mathrm{Yb}$ : YAG на воздухе приводит к уменьшению интенсивностей этих узких линий люминесценции.

В области спектра $320-850 \mathrm{~nm}$ ион $\mathrm{Yb}^{3+}$ не имеет полос поглощения и излучения. В $[21,22]$ показано, что эти узкие линии в керамике $\mathrm{Yb}: \mathrm{YAG}$ излучаются ионами $\mathrm{Yb}^{2+}$, стабилизированных кислородными вакансиями. Как следует из наших исследований, этот центр в поглощении является более активным, чем $F$-центр. На это указывает увеличение коэффициента поглощения в полосе при $\lambda \approx 455 \mathrm{~nm}$ спектра пропускания керамики Yb:YAG по сравнению с номинально чистой керамикой YAG (рис. 1). Отсутствие в спектре ИКЛ образцов Yb:YAG узких полос связанных радикалов $\mathrm{Y}=\mathrm{O}$ обусловлено уменьшением содержания пор в этих образцах по сравнению с беспримесными образцами YAG. Этот эффект связан с тем, что оксид иттербия в активированных образцах YAG выступает и в качестве спекающей добавки при синтезе керамики.

В спектре ИКЛ керамики Се:YAG сильная зеленая полоса при $\lambda \approx 560 \mathrm{~nm}$ однозначно связана с излучением иона $\mathrm{Ce}^{3+}$ на $d-f$-переходе [5,23]. В ультрафиолетовой области на фоне собственной полосы люминесценции при $\lambda \approx 320-350 \mathrm{~nm}$ проявляются сильные узкие полосы при $\lambda \approx 314$ и $360 \mathrm{~nm}$. Подобная структура УФ спектра наблюдается в рентгенолюминесценции [5]. Авторы [5] связывают первую полосу с излучением иона $\mathrm{Gd}^{3+}$, а вторую - $\mathrm{Tb}^{3+}$, как неконтролируемых примесей, входящих в керамику вместе с церием. Однако сильную полосу ИКЛ при $\lambda \approx 360 \mathrm{~nm}$ трудно приписать иону тербия. Действительно, в минералах ультрафиолетовая полоса излучения трехвалентного иона тербия 
на переходе ${ }^{5} D_{3} \rightarrow{ }^{7} F$ соответствует длине волны не короче $380 \mathrm{~nm}[19]$. Поэтому трудно найти причину сильного смещения полосы излучения (приблизительно на $1500 \mathrm{~cm}^{-1}$ ) иона редкоземельного элемента $\mathrm{Tb}^{3+}$ в YAG. Эта полоса при $\lambda \approx 360 \mathrm{~nm}$ может излучаться ионом $\mathrm{Ce}^{3+}$. Этот ион замещает ион $\mathrm{Y}^{3+}$ в додекаэдрической позиции. В этой позиции $d$-уровни иона церия расщепляются на орбитальный дублет $e_{g}$ (верхний) и триплет $t_{2 g}$ (нижний). Сильная зеленая полоса при $\lambda \approx 560 \mathrm{~nm}$ излучается на переходе $d\left(t_{2 g}\right) \rightarrow f$, в то время как $e_{g}$-компонента $d$-уровней может являться излучательным уровнем полосы при $\lambda \approx 360 \mathrm{~nm}$. Полагая, что в керамике Ce:YAG полоса поглощения при $\lambda \approx 300 \mathrm{~nm}$ соответствует переходу $f \rightarrow d\left(e_{g}\right)$, а полоса поглощения при $\lambda \approx 455 \mathrm{~nm}-$ переходу $f \rightarrow d\left(t_{2 g}\right)$ [5], находим величину расщепления $d$ уровней иона церия в $\mathrm{YAG}$ $\Delta v \approx 11355 \mathrm{~cm}^{-1}$. Эта величина вполне соответствует силе кристаллического поля в позиции примесного иона $\mathrm{Ce}^{3+}$ в YAG.

\section{Заключение}

В диапазоне 220-850 nm спектра импульсной катодолюминесценции керамических образцов оксида иттрия и YAG присутствуют три полосы собственной люминесценции: две сплошные при $\lambda \approx 320-350 \mathrm{~nm}$ и $\lambda \approx 510$ (490) nm и одна дискретная линейчатая полоса в области 600-730 nm.

Ультрафиолетовая полоса излучается автолокализованным экситоном, дырочной компонентой которого является молекулярный ион $\mathrm{O}_{3}^{-2}$, ассоциированный с катионными вакансиями $\mathrm{Y}^{3+}(\lambda \approx 350 \mathrm{~nm})$ и $\mathrm{Al}^{3+}$ $(\lambda \approx 320 \mathrm{~nm})$. Причем в оксиде иттрия реализуется центр одного типа с вакансией $\mathrm{Y}^{3+}$, а в YAG - центры двух типов, ассоциированные с вакансиями $\mathrm{Y}^{3+}$ и $\mathrm{Al}^{3+}$.

Зеленая полоса при $\lambda \approx 510 \mathrm{~nm}$ в YAG и $\lambda \approx 490 \mathrm{~nm} \mathrm{в}$ оксиде иттрия излучается $F$-центром.

Дискретная линейчатая полоса в номинально чистых оксиде иттрия и YAG в области 600-730 nm излучается связанными радикалами $\mathrm{Y}=\mathrm{O}$, локализованными на свободной поверхности пор.

Природа сильной полосы люминесценции при $\lambda \approx 360 \mathrm{~nm}$ в керамике Ce:YAG до конца не выяснена, наиболее вероятно, что она излучается на переходе $d\left(e_{g}\right) \rightarrow f$ иона $\mathrm{Ce}^{3+}$.

\section{Конфликт интересов}

Авторы заявляют, что у них нет конфликта интересов.

\section{Список литературы}

[1] Lu J., Yagi H., Takaichi K., Uematsu T., Bison J.-F., Feng Y., Shirakawa A., Ueda K.-I., Yanagitani T., Kaminskii A.A. // Laser. Appl. Phys. B. 2004. V. 79. P. 25.

[2] Ikesue A., Aung Y.L., Taira T., Kamimura T., Yoshida K., Messing. G.L. // Annu. Rev. Mater. Res. 2006. V. 36. P. 397.
[3] Багаев С.Н., Осипов В.В., Ватник С.М., Шитов В.А., Штейнберг И.Ш., Ведин И.А., Курбатов П.Ф., Лукьяшин К.Е., Максимов Р.Н., Соломонов В.И., Твердохлеб П.Е. // Квант. электрон. 2015. Т. 45. № 5. С. 492. doi 10.1070/QE2015v045n05ABEH015769

[4] Осипов В.В., Шитов В.А., Максимов Р.Н., Соломонов В.И., Лукьяшин К.Е., Орлов А.Н. // Фотоника. 2018. № 3. С. 318. doi 10.22184/1993-7296.2018.71.3.318.334

[5] Osipov V.V., Ishchenko A.V., Shitov V.A., Maksimov R.N., Lukyashin K.E., Platonov V.V., Orlov A.N., Osipov S.N., Yagodin V.V., Viktorov L.V., Shulgin B.V. // Opt. Mat. 2017. V. 71. P. 98. doi 10.1016/j.optmat.2016.05.016.

[6] Ильмас Э.Р., Кузнецов А.И. // ФТТ. 1972. Т. 14. № 5. C. 1464.

[7] Роозе Н.С., Анисимов Н.А. // Опт. и спектр. 1975. Т. 38. № 3. C. 627.

[8] Кузнецов А.И., Намозов Б.Р., Мюрк В.В. // ФТТ. 1985. T. 27. № 10. C. 3030.

[9] Vakhidov Sh.A., Rokov A.F. // Phys. Stat. Sol.(a). 1983. V. 80. N 2. P. 175

[10] Волженская Л.Г., Зоренко Ю.В, Пацаган Н.И., Пашковский М.В. // Опт. и спектр. 1987. Т. 63. № 1. С. 135.

[11] Зоренко Ю.В., Пашковский М.В., Батенчук М.М., Лимаренко Л.Н., Назар И.В. // Опт. и спектр. 1996. Т. 80. № 5. C. 776.

[12] Андрийчук А.А., Волженская Л.Г., Захарко Л.М., Зоренко Ю.В. // ФТТ. 1987. Т. 29. № 1. С. 232.

[13] Connor O. // Appl. Phys. Lett. 1964. V. 4. N 1. P. 126.

[14] Кузнецов А.И., Абрамов В.Н., Розе Н.С. // Письма в ЖЭТФ. 1978. Т. 28. № 5. С. 652.

[15] Бордун О.М., Бордун И.М., Новосад С.С. // ЖПС. 1995. T. 62. № 6. C. 91.

[16] Bordun O.M. // J. Appl. Spectr. (Belorus). 2001. V. 68. N 2. P. 304.

[17] Осипов В.В., Расулева А.В., Соломонов В.И. // Опт. и спектр. 2008. T. 105. № 4. C. 591.

[18] Solomonov V.I., Michailov S.G., Lipchak A.I., Osipov V.V., Shpak V.G., Shunailov S.A., Yalandin M.I., Ulmaskulov M.R. // Laser Physics. 2006. V. 16. N 1. P. 126.

[19] Таращан А.Н. Люминесценция минералов. Киев: Наукова думка, 1978. $296 \mathrm{c}$.

[20] Алукер Н.Л., Винникова Е.А. // Вестник КемГУ. Химия. 2008. № 2. C. 214.

[21] Соломонов В.И., Осипов В.В., Спирина А.В. // Опт. и спектр. 2014. Т. 116. № 3. С. 75.

[22] Solomonov V., Osipov V., Spirina A. // J. Luminescence. 2016. V. 169. P. 151.

[23] Полисадова Е.Ф., Тао Хан, Олешко В.И., Валиев Д.Т., Ваганов В.А., Шонши Джсанг, Бураченко А.Г. // Фундаментальные исследования. 2017. № 12 (ч. 1). С. 103. 